side is engraved the figure of a man on horseback. The horse is a ludicrous mixture of an English cart horse and a Norman destrier. The man is in armour as to his body and has an open sort of Roman helmet on his head; in his right hand he holds a lance, and to his left thigh is strapped a short curved falchion which looks like a Roman short sword. The bridle of the horse is a typical mediaeval structure and the reins appear to hang loose on the steed's neck. On the back of the snuff-box is engraved a coat-of-arms, the engraving being a typical example of the Chippendale period, very unlikely to belong to a date prior to 1750 . The coat may be blazoned as follows:-Gules, a lion rampant between three stars of six points argent. Crest, a demi-lion rampant. A previous owner has noted that this coat-of-arms is that of the Malone family; in this he is in error, the Malone coat being given by Burke as "Malone of Baronstown, Ireland, created Baron Sunderlin in 1785 : Gules, a lion rampant between three mullets argent." Now a mullet is a star of five points and it is almost inconceivable that such a mistake in elementary heraldry could have been made, unless it was engraved by an ignorant craftsman for an equally ignorant customer.

On the inside of the base of the box is stamped something which may be the remains of the marks for silver, but it is not possible to make anything of it. Read died in 1715 so that the silver must be at least as old as the reign of Queen Anne.

Sir William Read as a defender of the innocents appears in quite a new rôle; like most of the ophthalmic quacks all was fish that came to his net; he cured wens, hare-lips, cancers and cataracts and he was the proprietor of a noted styptic water, but we have never heard that he took babies under his care.

\title{
ANNUAL CONGRESS OF THE OPHTHALMOLOGICAL SOCIETY OF THE UNITED KINGDOM
}

\section{JUBILEE MEETING}

Mr. Leslie Paton, the president of the Ophthalmological Society of the United Kingdom, opened the Jubilee Meeting of the Annual Congress on Thursday, April 3, at the Royal Society of Medicine. On behalf of the Society he welcomed guests from Europe and America, and read messages of greeting from the following ophthalmic surgeons :-

Edward Jackson, Professor E. de Grosz, Professor Erlebeiman, Professor Vogt, Professor Axenfeld, Professor Fuchs, Professor Lundsgaard and others. 
Among those who offered addresses of congratulation were Professor de Schweinitz and Dr. Parker (U.S.A.), Professor Ovio (Padua), Professor van der Hoeve (Leyden), Professor Marquez (Madrid); Professor Meller (Vienna), Professor Terrien (Paris), Dr. Coppez (Brussels), Professor de Grosz (Budapest) and Professor Ask (Lund) who made a speech in Latin and presented two written addresses bound in leather, one from his own Ophthalmological Society and the other from his friend Professor Lundsgaard of the Danish Ophthalmological Society.

Presentation of the Nettleship Medal.-Miss Ida Mann was awarded the Nettleship Medal. 'The president paid a tribute to her distinguished career as a student and to the able work she has done on the embryology of the eye.

Presidential Address._-" The Control of Position and Movements of the Eyes."

Mr. Paton devoted his address to a consideration of the reflex factors which control the position and movements of the eyes. He said that in man and other animals with frontally placed eyes and binocular vision the retinal stimuli played a predominant part in such control, but in lower types with laterally placed eyes other factors came into prominence, the most important of these being reflex stimuli from the labyrinth and neck muscles. Mr. Paton used the term " dyscritic " for the lower controls and " epicritic" for the retinal and higher controls involving the cerebral cortex.

He described the physiological mechanism by which the body equilibrium, muscle tone, vision, and hearing were correlated in fishes and bats, and the part played by the sacculus and utriculus in the determination of certain ocular movements.

The relation between various postures of the head and ocular movements in rabbits was demonstrated by means of diagrams. Mr. Paton dealt briefly with the problem of nystagmus.

Professor van der Hoeve proposed a vote of thanks, which was seconded by Mr. Usher.

The Bowman Lecture.-Sir Arthur Keith, in a manner that is characteristic of his charming personality, delivered the Bowman Lecture on " The Genius of Bowman."

Sir William Bowman was the President of the Society fifty years ago. During his early years he made many brilliant discoveries in anatomy, and in the full tide of his professional life he did more than any other man in England to advance ophthalmology, a branch of medicine into which he was swept by force of circumstances.

Bowman lived in a period when medical knowledge was advancing with great rapidity. From his early days at King's College 
it is evident that he possessed those rare gifts of mind and heart that make a man great. He had a high view of his calling in life, and from his lectures to students it is obvious that his heart was with the poor and unfortunate.

For three years he shared the chair of physiology at King's College with his friend and master Professor Robert Bentley Todd, who exercised a powerful influence over the young men of promise who came into intimate contact with him. He was certainly the inspirer of Bowman.

At the conclusion of the lecture Sir Arthur Keith drew a parallel between Bowman and Lord Lister and pointed out the many striking resemblances between these two men. If general surgery suffered a great loss in the direction which fate gave to Bowman's career, ophthalmic surgery reaped an exceedingly great reward.

Mr. Lawford, who is an original member of the Society and as such has sat at the feet of Bowman, proposed a vote of thanks to Sir Arthur Keith.

Discussion.- " Disorders of Secretion of the Endocrine Glands associated with Eye Diseases."

The discussion was opened by Mr. J. H. FISHER, who said that it is now well established that the inter-relation between the functions of the endocrine glands is provided by the chief hormones which each supply, The hormones of some were antagonistic to, or corrective of, those of other glands, and an excess of one might stimulate the production of another. The balance between the whole group must be held if normal growth, health, and vitality were to be maintained.

Professor H. MacLean said that little was known about the endocrine glands, and the various reactions which took place in such a condition as diabetes. The recent work which has been done on carbohydrate metabolism shows that the views held up to a year or two ago are wrong. In his opinion, the fundamental difficulty in a case of progressive diabetes was in the failure of the tissues to utilize or burn up sugar.

Professor E. C. Dodds said that it was impossible to correlate the basal metabolic rate with the amount of exophthalmos, and that exophthalmos might advance or recede irrespective of the general condition. His observations confirmed the view that diabetic retinitis occurred only with associated arterial degeneration.

Dr. Clark Souter showed some interesting charts and pictures of clinical cases. Mr. A. W. Ormond and Mr. C. Goulden contributed to the discussion. 
Papers.-A full account of the papers and demonstrations will be in the Transactions of the Ophthalmological Society. Only a brief summary of these papers is given here.

Mr. E. Treacher Collins read a paper on the Harderian gland, xerophthalmia, vitamin A deficiency, and keratomalacia. He described the embryology, anatomy, and function of the Harderian gland.

DR. W. R. Aykroyd gave an interesting account of his experiences of night blindness due to vitamin deficiency in Newfoundland and Labrador fishermen. These men live on a diet deficient. in eggs, butter, and green vegetables. Two doses of cod-liver oil restored the vision, and the ingestion of sea-gulls' liver while at sea acted as a prophylactic in some cases.

Dr. JAMEs Collier read a paper on " Ocular paralyses " resulting from infective or toxic processes, such as diphtheria, polyneuritis, botulism, and veronal intoxication.

Mr. TUDOR THOMAS gave a report and demonstration of his experiments in "Transplantation of the Cornea " carried out on rabbits in the Physiological Department of the Welsh National School of Medicine. In his experience the best results were obtained by cutting circular grafts with shelving edges. The graft was slightly smaller than its bed, and was held in place by stitches inserted into the adjacent cornea and crossing the graft in the pattern of a Maltese cross. Sterile olive oil is instilled into the eye. Out of 14 experiments carried out in this manner, 13 of the grafts united, 4 grafts were clear, and the four rabbits with clear corneal grafts were demonstrated at the meeting. The demonstration evoked a great deal of interest.

Professor Ask (Lund) said that he had used a flap of conjunctiva to hold the graft in position.

Dr. Mulock Houwer read a paper on "The Aetiology of Retention Cysts of the Fornix Conjunctivae " illustrated by microphotographs.

Mr. Duke-Elder gave an account of experimental work which demonstrated the effect of choline and acetyl-choline on the extrinsic muscles of the eye. During research upon the effects of various drugs on the intra-ocular circulation it was discovered that choline produced reactions in the intra-ocular pressure. Choline excites a contraction in the extra-ocular muscles, which was unaffected by atropine and abolished by nicotine and curare.

Mr. Juler described " Some cases of damage to Descemet's Endothelium" which had occurred during a wash-out of the anterior chamber. He showed illustrations of corneal dystrophy which had occurred in two sisters.

PROFESSOR VAN DER HOEve read an interesting paper on "The Fye and Amnion Bands." He described the relation between facial defects and abnormalities of the lacrymal passages caused by the 


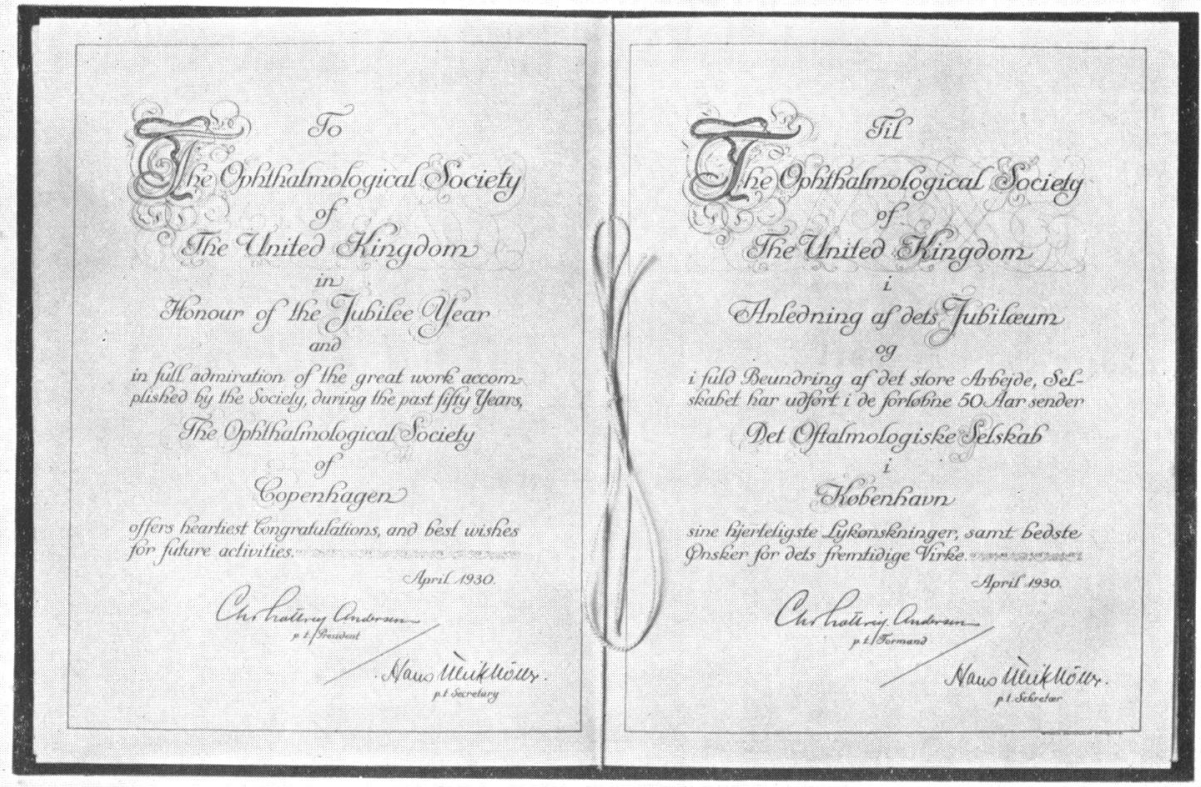

Photograph of the Address presented to the Ophthalmological Society of the United Kingdom on the occasion of the Fiftieth Anniversary by the Council of the Ophthalmological Society of Copenhagen.

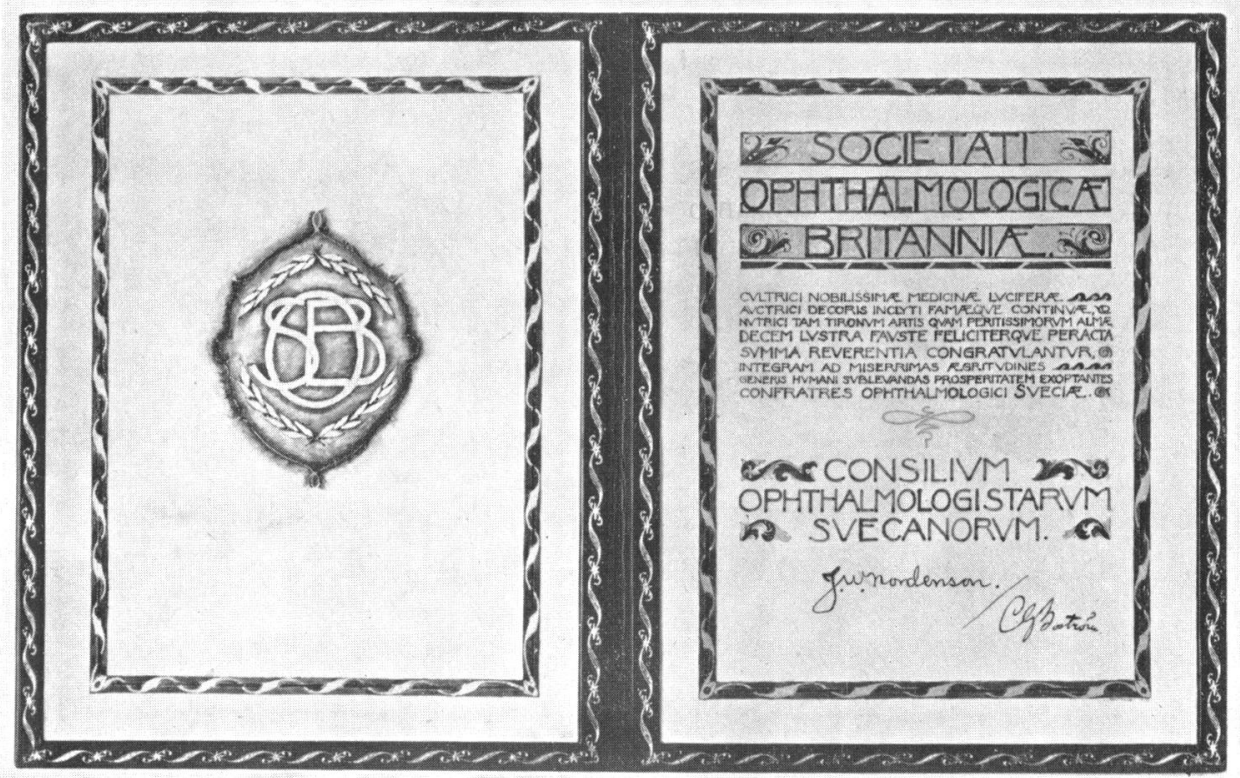

Photograph of the Address presented to the Ophthalmological Society of the United Kingdom on the occasion of its Fiftieth Anniversary by the Council of the Ophthalmological Society of Sweden. 


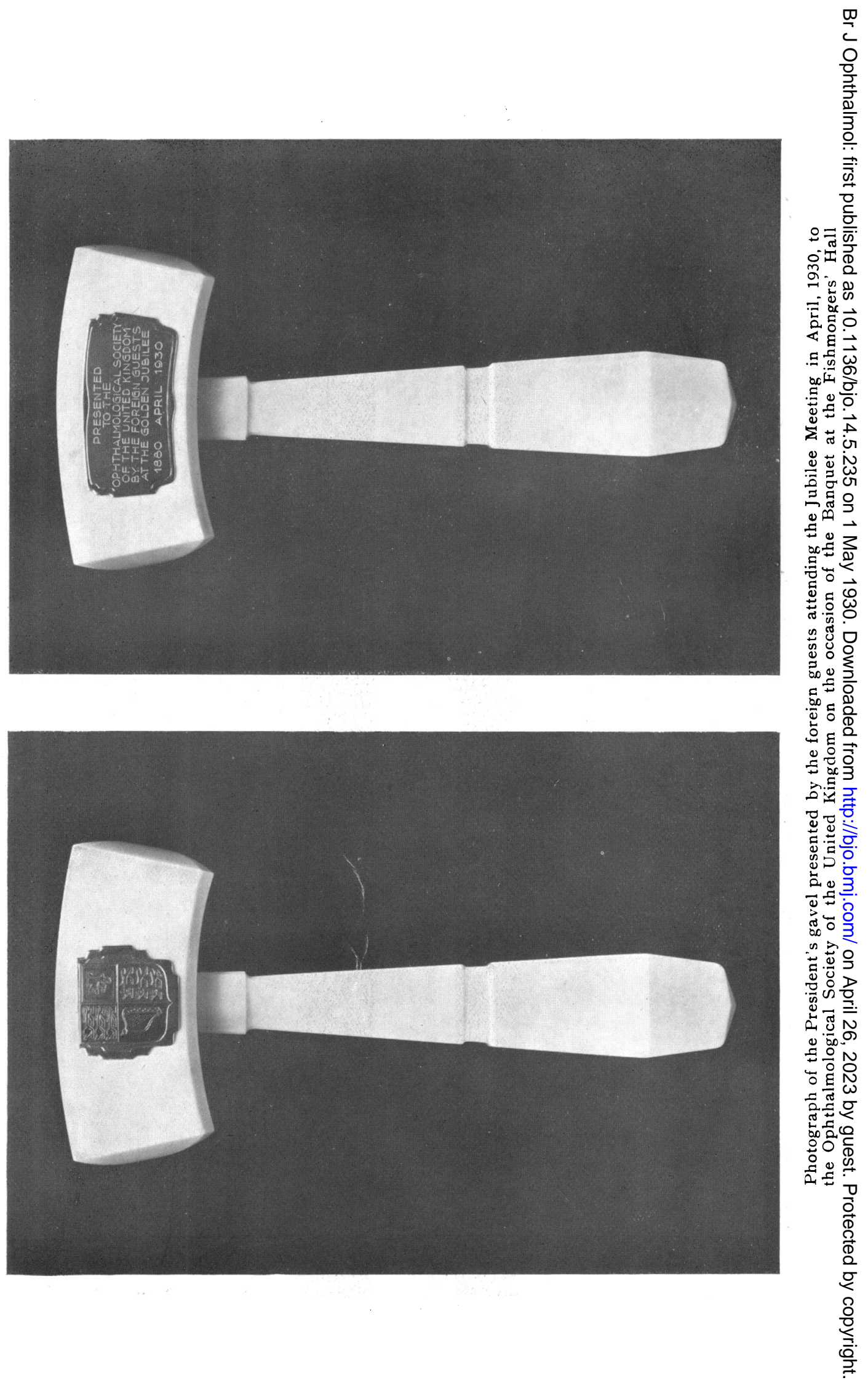


presence of amnion bands, which by pressure had brought about an arrest or failure of development of structures in their vicinity. Some interesting photographs were shown to illustrate these defects in association with the presence of an amnion band and remnants of foetal membranes.

Professor G. Marquez read a paper on " La Theorie Stereoscopique des Anaglyphes " illustrated by stereoscopic slides.

Mr. Cha.vasse gave a survey of the existing theories of convergent concomitant strabismus, together with some observations on the antiquity of stereopsis. He criticised the " accommodation," the "muscular," and the "fusion faculty" theories. $\mathrm{He}$ believes that a number of convergent squints are due to paralysis at birth, the paralytic squint masquerading as concomitant. $\mathrm{He}$ showed statistics of the ratio of convergent strabismus to a refractive error in 200 normal children and in 200 squinting children. The higher the hypermetropia the greater the liability to squint, but there is no relation between hypermetropia and the degree of squint. In his opinion the accommodation theory is not supported by tests and has little to do with squint. He believes that a departure from the normal refraction and ocular inequality are of primary importance, and that not one anomaly but various anomalies may cause a squint.

Professor van der Hofve and Dr. Maddox took part in the discussion.

Miss Mann read a paper on "The Reptilian Iris " which was illustrated by numerous beautiful hand paintings. Five types of vascular pattern were demonstrated. This work has been done on telapins, geckos, lizards, snakes, and frogs.

Dr. GORDON Holmes read a paper on the "Spasm of fixation," which was of great interest from a neurological point of view.

DR. ADIE gave an account of his experience with 92 patients suffering from acute retrobulbar neuritis in disseminated sclerosis. 34 per cent. of these showed definite signs of disseminated sclerosis, 50 per cent. complained of mistiness of vision.

Sir ARnold Lawson gave a further note on a case of bilateral symmetrical detachment of the retina with $6 / 5$ vision (Rep. in Vol. XLIV, p. 96, Trans. Ophthal. Soc. U.K.).

Mr. Bernard Cridland made some comments on the certified causes of blindness. He suggested that a true record should be kept of all such cases, stating the cause of the blindness, and that certificates should be signed only by medical men trained in ophthalmology.

Mr. AfFleck Greeves gave a survey of the value of X-ray therapy in superficial keratitis.

Mr. DogGart described some cases of ocular rosacea and discussed the treatment of this condition. 
Mr. RiDley gave an account of his experimental work in connection with the intra-ocular pressure and the drainage of the aqueous. Specimens were demonstrated in the museum of the Congress.

Mr. G. F. Alexander read a paper on " Discission of aftercataract." He recommends extraction of the after-cataract instead of needling in cases where the capsular remnants are thick.

DR. Rosa FORD described the method she adopts for scotometry at two metres.

Exhibition.-There was an exhibition of optical apparatus by the dispensing opticians, and surgical instruments by John Weiss \& Son, Ltd.

Museum.-Pathological specimens and slides showing morbid histology were on view together with other objects of interest.

Reception by the President and Council of the Royal College of Surgeons at the Royal College of Surgeons.-On the first evening of the Congress a reception was given at the Royal College of Surgeons. The visitors were received by Lord Moynihan, the President, and Mr. C. H. Fagge and Mr. Warren Low, the VicePresidents. Sir D'Arcy Power and the curators had collected and displayed instruments, books, engravings, spectacles and other objects of historical interest to ophthalmic surgeons. Sir William Bowman's microscope was there together with a collection of his slides demonstrating the anatomy and morbid histology of the eye.

The Congress Banquet.-This banquet was held at Fishmongers' Hall. Mr. Leslie Paton presided and 150 were present. The President proposed the " Health of the Society" and traced its history back to a little group of energetic men who used to meet in the house-surgeon's room at Moorfields to discuss ophthalmic matters.

There were 114 original members of the Society, of whom 11 were still alive, and two of them, Sir Thomas Barlow and Mr. J. B. Lawford, were present.

Sir Thomas Barlow gave an account of the Society in its early days.

Sir John Parsons in a witty speech proposed the health of the Bowman Lecturer, and Sir Arthur Keith, in reply, praised the ophthalmological schools in this country.

Mr. J. H. Fisher proposed the health of the guests, to which Professor van der Hoeve made a charming response, and in the name of the foreign visitors presented the Society with an ivory gavel suitably inscribed: 
Sir John Bland-Sutton also responded for the guests.

The President's health was proposed and thanks were expressed to the Prime Warden of the Fishmongers' Company whose splendid hall gave a dignified setting to such a memorable occasion.

The final event of the Congress was a visit to the Zoological Gardens, where Miss Mann demonstrated the slit-lamp appearances of the reptilian iris and the fundi of frogs and lizards. The visitors were entertained to tea in the Fellows' Pavilion.

\section{H. B. Stallard.}

\section{ABSTRACTS}

\section{I. -UVEAL TRACT}

(1) Heckel, Edward B. (Pittsburgh, Pa.).-Diphtheria antitoxin in large doses for sympathetic ophthalmia. Arch. of Ophthal., January, 1928.

(1) Heckel recognises two types of sympathetic ophthalmitis, the first consisting of anterior uveitis with more or less occlusion of the pupil, the second of neuro-retinitis, the pupil remaining quite clear. Two cases of each type are described in the text. The first was interesting in that sympathetic ophthalmitis developed although the exciting eye was removed within a fortnight of the injury, vision being reduced by neuro-retinitis to counting fingers at four feet. 3,000 units of diphtheria antitoxin were given and repeated four times with such improvement in vision, that 6 weeks after the appearance of the disease it came up to $20 / 20$. Seven months later the vision was the same. The second case was also of the neuro-retinitic type with reduction of vision to 10/200. He was treated first with neo-salvarsan then with mercury, and vision became 20/30 going down again four years later to $5 / 200$. Injection of diphtheria antitoxin and the administration of mercury resulted in improvement up to $20 / 200$. The third case was given 5,000 units daily for 10 days with possibly some visual improvement and the fourth case 20,000 units daily for 7 days which resulted in an improvement of vision from $2 / 200$ to $6 / 200$.

$$
\text { F. A. W.-N. }
$$

(2) Brown, Albert L. (Cincinnati).-Subconjunctival injections of atropin and adrenalin in iridocyclitis. Amer. Jl. of Ophthal., February, 1929.

(2) Brown advocates the subconjunctival injection of adrenalin and atropine in cases of iridocyclitis with unyielding synechiae. 